\title{
Effects of Contact Normal Bond Strength on Brazilian Tensile Strength by Particle Flow Code
}

\author{
Chunlei Huang ${ }^{1}$, Yan Fu ${ }^{2, *}$, Luli Miao ${ }^{3}$ and Vernon Ireland ${ }^{4}$ \\ ${ }^{I}$ Faculty of transportation and municipal engineering, Chongqing Jianzhu College, Chongqing 400072, China \\ ${ }^{2}$ School of Management Science and Real Estate, Chongqing University, Chongqing 400045, China \\ ${ }^{3}$ School of Civil engineering, Chongqing University, Chongqing 400045, China \\ ${ }^{4}$ Faculty of Engineering, Computer and Mathematical Sciences, The University of Adelaide, Adelaide, South Australia 5005, Australia
}

Received 4 November 2019; Accepted 17 January 2020

\begin{abstract}
The Contact Bond Model (CBM) of Particle Flow Code (PFC) can effectively simulate the mechanical behaviours of rocks. The physical and mechanical parameters of CBM directly influence the results of the numerical simulation of rocks. To reveal the influence mechanism of the contact normal bond strength of the CBM on Brazilian tensile strength, this study proposes a numerical test model and calculation method for the Brazilian tensile strength. First, the theoretical relationship between the Brazilian tensile strength and the contact normal bond strength of the CBM was derived. Second, 70 groups (350) of PFC Brazilian disk numerical tests were designed, and a numerical model of the Brazilian tensile strength was established. Third, the effects of the contact normal bond strength on the Brazilian tensile strength under various ball radii and ball radius ratios were analyzed according to the PFC numerical simulation results, and the correctness of the theoretical relation was verified. Results demonstrate that the Brazilian tensile strength is significantly and linearly related to the contact normal bond strength and can be expressed as the product of the contact normal bond strength and the scale coefficient. The scale coefficient is affected by the geometric parameters of balls. The scale coefficient generally increases with the minimum particle size, whereas the change in the coefficient becomes irregular. Results reveal the physical significance of the PFC normal bond strength to a certain extent. The proposed method can determine the contact normal bond strength.
\end{abstract}

Keywords: Particle flow code, Contact bond model, Contact normal bond strength, Brazilian tensile strength, Scale coefficient

\section{Introduction}

As a discrete element method based on the micromechanical properties of granular media, particle flow code was widely used to simulate loose media, such as sand and pebble, at an early stage. Potyondy and Cundall [1] proposed a bonded particle model suitable for rock and BPM, which successfully explained the physical mechanism of shear failure and the compression-induced tensile fracture of rock at the particle scale, making PFC a powerful tool for analyzing the complex mechanical behaviors of rocks. Two BPM models can describe the micro-mechanical properties of rock. One is the contact bond model (CBM), and the other is the parallel bond model (PBM). As a simplified model of PBM, CBM was widely used for the numerical simulation of uniaxial compression, biaxial compression, and Brazilian tensile tests, which can completely obtain the failure process, crack development, and stress-strain curve.

However, in comparison to the macro-mechanical parameters of rock, the micro-mechanical parameters of CBM cannot be directly determined in laboratory tests. The physical meaning is also unclear. Using the Mohr-Coulomb model as an example, the parameters describing the macroshear properties of rock include cohesive force, internal friction angle, and the parameter describing the macrotensile properties of rock, such as tensile strength. The parameters can be measured via indoor triaxial shear tests

*E-mail address: henry.quake.fu@163.com

ISSN: 1791-2377 @ 2020 School of Science, IHU. All rights reserved. doi:10.25103/iestr.131.05 and Brazilian split test. The parameters of CBM describing the micro-shear properties of rocks include the contact shear bond strength and friction coefficient, whereas the contact normal bond strength describes the microscopic tensile properties of rock. The parameters can only be determined by macro-mechanical parameters. The "trial and error method" recommended in the PFC Manual [2] is a widely used calculation method, but it consumes substantial time and energy. The effects of the micro-mechanical parameters of CBM on macro-mechanical parameters not only have proven the physical symbol of micro-mechanical parameters but have also provided a method to determine micromechanical parameters.

Second, in comparison to the finite element simulation of rock, the results of rock PFC simulation are influenced by particle geometric parameters (ball radius and ball radius ratio) and particle mechanical parameters (contact normal bond strength, contact shear bond strength, and friction coefficient). The micro-mechanical parameters of CBM have complex influence on macro-mechanical parameters.

Scholars conducted numerous studies on the effects of PFC micro-mechanical parameters on macro-mechanical parameters [3-7], which focused on the comprehensive effects of micro-mechanical parameters on macromechanical parameters. However, they failed to reveal the influence mechanism of micro-mechanical parameters representing the same physical property on macromechanical parameters at various scales, such as the influence of the contact normal bond strength representing the tensile properties of rock on Brazilian split strength, 
along with the effects of the contact shear bond strength and friction coefficient representing the shear properties of rock on cohesion and internal friction angle. Therefore, studies should urgently reveal the influence mechanism of micromechanical parameters that represents the same physical property on macro-mechanical parameters and obtain the influence law of micro-mechanical parameters on macromechanical parameters.

Based on the analysis with the macro- and micromechanical parameters that represent the tensile properties of rock as the study objects, the current study systematically investigates the effect of contact normal bond strength on Brazilian tensile strength. Through a theoretical derivation and PFC numerical simulation, a numerical test model for tensile strength was established. In addition, the influence of the contact normal bond strength on the Brazilian tensile strength was analyzed, expecting to obtain the influence mechanism of the contact normal bond strength on the Brazilian tensile strength and provide a new method for determining the contact normal bond strength.

\section{State of the Art}

Scholars worldwide conducted a series of studies on the effects of micro-mechanical parameters on macromechanical parameters from three aspects. First, through the uniaxial and biaxial compression PFC numerical simulation of rock, the influence laws of micro-mechanical parameters on uniaxial and biaxial compressive strength of rock were examined. Representative studies include Yang et al. [8], who used PFC to simulate the uniaxial compression test of rock and explored the comprehensive effects of micromechanical parameters on uniaxial compressive strength, Young modulus, and Poisson's ratio of rock by conducting a statistical analysis. Moreover, they established a dimensionless quantitative relationship between macro- and micro-mechanical parameters. However, they ignored the effect of tensile strength of rock. According to Ding et al. [9], when the average particle size of the PFC3D model is constant, the uniaxial compressive strength of rock increases with particle size ratio, whereas Young modulus and Poisson's ratio decreases. However, their study simulated the uniaxial compression tests of rock, instead of tensile properties. Based on the PBM model, Nohut et al. [10] conducted a stepwise regression analysis to obtain the fitting relationship between macro-mechanical (Young modulus, Poisson's ratio, and compression resistance strength) and micro-mechanical parameters. They innovated the regression method of the calculation results but continued to simulate the uniaxial compressive strength of rock. Wong et al. [11] pointed out that the fracture stress decreased with particle size, whereas the uniaxial compressive strength did not significantly correlate with particle size. However, the quantitative relationship between macro- and micro- strength was not established. By conducting the uniaxial and biaxial compression tests of rock, $\mathrm{Li}$ et al. [12] proposed a method for determining micro-parameters based on bisection iteration and verified the method using mylonite; they discussed the effects of the shear strength parameters of rock, but tensile strength parameters were not involved. Afolagboye et al. [13] and Wang et al. [14] examined the effects of the crack angle and the hole on uniaxial compressive strength of rock, but they did not discuss the effect of the contact normal bond strength on Brazilian tensile strength. Mehranpour et al. [15] used 29 PFC models to conduct true triaxial numerical tests on rock and verified six rock failure criteria, but the effect of micro-strength on macro-strength was neglected. Second, based on the design of experiment theory, the PFC model of rock was simulated, while the effects of micro-mechanical parameters on macromechanical parameters were determined, according to the compression experiment results. Representative studies include Jeoungseok [16], who used the Plackett-Burman design method to analyze the effects of micro-mechanical parameters of rock on macro-mechanical parameters in CBM, obtaining the quantitative relationship between the macro-parameters (uniaxial compressive strength, Young modulus, and Poisson's ratio) and micro-parameters (contact normal bond strength, contact shear bond strength, and contact modulus) based on CCD (Central Composite Design). Their method has high calculation accuracy, but the calculation process was complicated. Moreover, they did not study the effects of micro-mechanical parameters on tensile strength. Based on the PBM model of PFC3D, Deng et al. [17] used the Plackett-Burman design method and response surface method to obtain the nonlinear relationship between macro response (uniaxial compressive strength, elastic modulus, and Poisson's ratio) and micro-mechanical parameters. Mathematical programming was used to optimize the solution and obtain the method for determining micro-parameters of hard rock. Their calculation method is complex, while the fitted quadratic term cannot explain the physical meaning of the micro-mechanical parameters.

Third, the effects of particle size, model size, and microstrength parameters on the Brazilian tensile strength were examined. Representative studies include: $\mathrm{Xu}$ et al. [18], who used a 3D flat-joint model of PFC3D to analyze the effect of micro-mechanical parameters, including the model size, model resolution, and the degree of heterogeneity on the Brazilian tensile strength, revealing that the contact normal bond strength has a significant influence on the Brazilian tensile strength and direct tensile strength. However, the quantitative relationship between the contact normal bond strength and Brazilian tensile strength and direct tensile strength was not established. Castro-Filgueira et al. [19] found that the contact normal bond strength has a high influence on Brazilian tensile strength, while the stiffness ratio has a high influence on Poisson's ratio. Their study used a constant value of ball radius ratio, which influenced the universality of the calculation results. Chen [20] revealed a linear correlation between the tensile strength of rock and the contact normal bond strength by conducting uniaxial tensile numerical experiments of 32 PFC models, but they did not discuss the influence of the ball radius ratio on the simulation results. Wu et al. [21] discussed the influence of the geometric parameters on the Brazilian tensile strength using a 3D flat-joint model of PFC3D. Results show that only when the diameter of the Brazilian disc is at least 20 times the ball radius can the dispersion of the results be eliminated, but the effects of the contact normal bond strength on the Brazilian tensile strength were ignored. Torabi et al. [22] and Yang et al. [23] examined the theoretical value and the measured value of stress distribution in a circular ring from the perspective of fracture mechanics, revealing that the maximum tensile strength of a single-hole disc decreased with the increasing ball radius ratio. However, they neglected the effect of the contact normal bond strength on the maximum tensile strength. Akram et al. [24] discussed the effects of particle distribution and particle size on the uniaxial, triaxial, and Brazilian tensile strength of clastic rocks, but they did not 
discuss the effect of the contact normal bond strength on the Brazilian tensile strength.

The studies have investigated the effect of shear strength and compressive strength of rock, but few studies have focused on the effect of tensile strength. The effect of tensile strength of rock was qualitatively examined, while the effect of the contact normal bond strength on Brazilian tensile strength has been ignored. This study has established the theoretical relationship between the contact normal bond strength and the Brazilian tensile strength, designing the Brazilian disc numerical simulation tests with various ball radiuses, ball radius ratios, and contact normal bond strength The influence law of the contact normal bond strength on the Brazilian tensile strength was discussed according to the PFC numerical test results, while the quantitative relationship was established and verified by examples.

The remainder of this study is organized as follows. Section 3 derives from the theoretical relationship between the contact normal bond strength and the Brazilian tensile strength. Based on this relationship, 70 groups (350) of Brazilian tensile tests are designed and a series of numerical test models of the Brazilian tensile strength are established. Section 4 analyzes the numerical simulation results of the Brazilian tensile test and discusses the influence law of contact normal bond strength on Brazilian tensile strength. The quantitative relationship between the contact normal bond strength and the Brazilian tensile strength is determined. Moreover, the adaptability of the relationship is verified by five cases. Finally, Section 5 summarizes the study and drew the conclusions.

\section{Methodology}

\subsection{Theoretical relationship between Contact Normal} Bond Strength and Brazilian Tensile Strength

Jeoungseok [16] derived the potential relationship between the contact normal bond strength $\sigma_{\mathrm{cn}}$ characterizing the tensile properties of particles and the fracture toughness $K_{\text {IC }}$ of rock. Liu et al. [25] determined the relationship between the I-type fracture toughness $K_{\text {IC }}$ and the contact normal bond strength $\sigma_{\mathrm{cn}}$ characterizing the micro-tensile properties based on the strain energy of the equivalent micro-beam model of two balls (Figure 1), as shown in Eq. (1):

$$
K_{\mathrm{IC}}=\sigma_{\mathrm{cn}} \sqrt{\frac{R_{\mathrm{A}}}{4 \beta} \frac{(1+\alpha)^{3}}{\alpha}}
$$

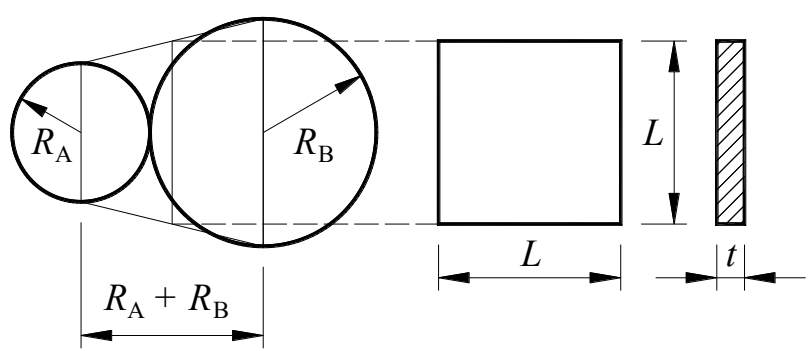

Note: $R_{\mathrm{A}}$ is the radius of the smaller ball, $R_{\mathrm{B}}$ is the radius of the bigger ball, $L$ is the span and height of the equivalent micro-beam, and $t$ is the width of the equivalent micro-beam.

Fig. 1. Equivalent micro-beam in CBM where $K_{\mathrm{IC}}$ is the I-type fracture toughness of the rock $\left(\mathrm{MPam}^{1 / 2}\right), \sigma_{\mathrm{cn}}$ is the contact normal bond strength of the $\mathrm{CBM}(\mathrm{MPa}), R_{\mathrm{A}}$ is the radius of the smaller particles $(\mathrm{m})$, $\alpha$ is the ball radius ratio $R_{\max } / R_{\min }$ (dimensionless), and $\beta$ is the ratio of Ball-to-ball Contact Modulus to Young's modulus (dimensionless).

Zhang [18] established the relationship between the macro tensile strength $\sigma_{\mathrm{t}}$ and the fracture toughness $K_{\mathrm{IC}}$ according to the statistical analysis results, as shown in Eq. (2):

$$
\sigma_{\mathrm{t}}=6.88 K_{\mathrm{IC}}
$$

where $\sigma_{\mathrm{t}}$ is the tensile strength of rock $(\mathrm{MPa})$ and $K_{\text {IC }}$ is the I-type rock fracture toughness $\left(\mathrm{MPam}^{1 / 2}\right)$.

Based on the discussion, it can be inferred from Equations (1) and (2) that the contact normal bond strength $\sigma_{\mathrm{cn}}$ characterizing the tensile properties of particles was related to the Brazilian tensile strength $\sigma_{t}$. Eq. (1) was substituted to Eq. (2) to obtain Eq. (3):

$$
\sigma_{\mathrm{t}}=6.88 K_{\mathrm{IC}}=6.88 \sqrt{\frac{R_{\mathrm{A}}}{4 \beta} \frac{(1+\alpha)^{3}}{\alpha}} \times \sigma_{\mathrm{cn}} \Rightarrow \sigma_{\mathrm{t}} \propto \sigma_{\mathrm{cn}}
$$

Eq. (3) shows that when the ball radius, ball radius ratio, and macro-ball-to-ball contact modulus ratio are unchanged, the macro-tensile strength $\sigma_{\mathrm{t}}$ of the rock is proportional to the micro-contact normal bond strength $\sigma_{\mathrm{cn}}$. Eq. (3) theoretically proving the study results of $\mathrm{Xu}$ et al. [18], Castro-Filgueira et al. [19], and Chen [20], in which the contact normal bond strength has a significant influence on the Brazilian tensile strength.

Based on Eq. (3), this study focused on the contact normal bond strength and Brazilian tensile strength of CBM and established a Brazilian disc PFC numerical model with various micro-mechanical parameters to investigate the influence law of the contact normal bond strength on Brazilian tensile strength.

\subsection{Selection of Bonded Particle Model in Particle Flow Code 2D}

In Particle Flow Code 2D (PFC2D) numerical simulation, there are two types of Bonded Particle Models (BPM) simulating the micro-mechanical properties of rock: Contact Bond Model (CBM) and Parallel Bond Model (PBM). As a simplification of PBM, CBM has five micro-mechanical parameters and seven parallel bonding parameters, which are shown in Table 1. Studies [16-17] show that it is feasible to use simplified CBM to simulate the mechanical behaviors of rock.

A total of seven independent parameters are required to establish a CBM, including two geometric parameters (minimum particle size $R_{\min }$, ball radius ratio $R_{\max } / R_{\min }$ ), and three strength parameters (friction coefficient $\mu$, contact normal bond strength $\sigma_{\mathrm{cn}}$, contact shear bond strength $\tau_{\mathrm{cs}}$ ), and two stiffness parameters (contact modulus 
$E_{\mathrm{c}}$, stiffness ratio $k_{\mathrm{n}} / k_{\mathrm{s}}$ ). To study the effect of the contact normal bond strength on the Brazilian tensile strength, this study has set the contact normal bond strength $\sigma_{\mathrm{cn}}$, minimum ball radius $R_{\min }$, and ball radius ratio $R_{\max } / R_{\min }$ as the test variables, as shown in Table 2.

Table 1. Micro-parameters of BPM in PFC2D

\begin{tabular}{c|c|c|c|c|c|c}
\hline \multicolumn{2}{c|}{ Type of Model } & Micro-parameters of & \multicolumn{2}{c|}{ Micro-parameters of Stiffness } & \multicolumn{2}{c}{ Micro-parameters of Strength } \\
\cline { 4 - 6 } & Grain & Grains & Cement & Grains & Cement \\
\hline \multirow{2}{*}{$\begin{array}{c}\text { Bonding } \\
\text { material }\end{array}$} & Contact Bond Model & $\rho, R_{\min }, R_{\max }$ & $E_{\mathrm{c}}, k_{\mathrm{n}} / k_{\mathrm{s}}$ & $/$ & $\mu$ & $\sigma_{\mathrm{cn}}, \tau_{\mathrm{cs}}$ \\
& Parallel Bond Model & $\rho, R_{\min }, R_{\max }, \bar{\lambda}$ & $E_{\mathrm{c}}, k_{\mathrm{n}} / k_{\mathrm{s}}$ & $\bar{E}_{\mathrm{c}}, \bar{k}_{\mathrm{n}} / \bar{k}_{\mathrm{s}}$ & $\mu$ & $\bar{\sigma}_{\mathrm{cn}}, \bar{\tau}_{\mathrm{cs}}$ \\
\hline
\end{tabular}

Table 2. Micro-parameters of Contact Bond Model

\begin{tabular}{c|l|c|c}
\hline \multicolumn{2}{c|}{ Micro-parameters of CBM } & $\begin{array}{c}\text { Test } \\
\text { constants }\end{array}$ & $\begin{array}{c}\text { Test } \\
\text { variables }\end{array}$ \\
\hline $\begin{array}{c}\text { Geometric } \\
\text { Parameters }\end{array}$ & $\begin{array}{l}\text { Minimum Ball Radius: } R_{\min } \\
\text { Ball Radius Ratio: }\end{array}$ & & $\sqrt{ }$ \\
& $R_{\max } / R_{\min }$ & & \\
\hline Strength & Contact Normal Bond & & $\sqrt{ }$ \\
Parameters & $\begin{array}{l}\text { Strength: } \sigma_{\mathrm{cn}} \\
\text { Contact Shear Bond }\end{array}$ & $\sqrt{ }$ & \\
& $\begin{array}{l}\text { Strength: } \tau_{\mathrm{cs}} \\
\text { Ball Friction Coefficient: } \mu\end{array}$ & $\sqrt{ }$ & \\
\hline Parameters & $\begin{array}{l}\text { Ball-to-ball Contact } \\
\text { Modulus: } E_{\mathrm{c}}\end{array}$ & $\sqrt{ }$ & \\
& Stiffness ratio: $k_{\mathrm{n}} / k_{\mathrm{s}}$ & $\sqrt{ }$ & \\
\hline
\end{tabular}

3.3 Micro-parameters of Contact Bond Model in PFC2D According to the Suggested Methods for Rock Mechanics Test of ISRM [27] and China's Standard for Test Methods of Engineering Rock Masses (GB / T 50266-2013) [28], the particle flow test specimen was a disc with a diameter of $50 \mathrm{~mm}$. Based on [27-28], the thickness of the test specimen should be 0.5-1.0 times the diameter and greater than 10 times the maximum ball radius of the rock. For threedimensional models, the maximum ball radius of the test specimen should be smaller than $2.5 \mathrm{~mm}-5 \mathrm{~mm}$.

According to Shi et al [29], in the axial compression test of the particle flow test specimens, as the particle size decreases, the uniaxial compressive strength of the specimen tends to be stable and no longer changes with the change of particle size. It is recommended that the ratio of the shortest side of the model to the average ball radius of the model should be greater than 40 , which is much larger than the value recommended by $\mathrm{Wu}$ et al [21]. Combined with this test, the average ball radius was less than $50 \mathrm{~mm} / 40=$ $1.25 \mathrm{~mm}$. In PFC2D, decreasing the ball radius can rapidly increase the total number of particles. Therefore, the minimum ball radius of the test specimen should be selected according to the computing capacity of the computer. This study has set the minimum particle size to $0.1 \mathrm{~mm}$. To study the effect of geometrical parameters on macro- and microtensile strength, the maximum ball radius is $4 \mathrm{~mm}$ and the ball radius in the simulation of rock specimen ranges from $0.1 \mathrm{~mm}$ to $4 \mathrm{~mm}$.
According to the simulation experience of particle flow, when the contact normal contact strength is less than the shear contact strength, it is easier to obtain a numerical specimen conforming to the mechanical properties of rock, in which the ratio of contact normal bond strength to contact shear bond strength should be less than 1. Referring to the micro-parameters of rock simulated by Liu et al. [25], the contact modulus of CBM is $10 \mathrm{GPa}$, the stiffness ratio is 3.5 , the friction coefficient is 1.7 , and the contact shear bond strength is $50 \mathrm{MPa}$.

Table 3. Value of micro-parameters of CBM

\begin{tabular}{|c|c|c|}
\hline & Diameter of Brazilian Disk: $D(\mathrm{~mm})$ & 50 \\
\hline $\begin{array}{l}\text { Geometric } \\
\text { Parameters }\end{array}$ & $\begin{array}{l}\text { Minimum Ball Radius: } R_{\min }(\mathrm{mm}) \\
\text { Ball Radius Ratio: } R_{\max } / R_{\min }\end{array}$ & $\begin{array}{c}0.10,0.15 \\
0.20,0.25 \\
0.30,0.35 \\
0.40 \\
1,2,3,4,5 \\
6,7,8,9,10\end{array}$ \\
\hline $\begin{array}{c}\text { Strength } \\
\text { Parameters }\end{array}$ & $\begin{array}{l}\text { Contact Normal Bond Strength: } \\
\sigma_{\mathrm{cn}}(\mathrm{MPa}) \\
\text { Contact Shear Bond Strength: } \\
\tau_{\mathrm{cs}}(\mathrm{MPa}) \\
\text { Strength Ratio: } \sigma_{\mathrm{cn}} / \tau_{\mathrm{cs}} \\
\text { Ball Friction Coefficient: } \mu\end{array}$ & $\begin{array}{c}1,5,15,20, \\
30 \\
50 \\
\\
0.02,0.1, \\
0.3,0.4,0.6 \\
1.7\end{array}$ \\
\hline $\begin{array}{l}\text { Stiffness } \\
\text { Parameters }\end{array}$ & $\begin{array}{lll}\text { Ball-to-ball Contact } & \text { Modulus: } \\
E_{\mathrm{c}}(\mathrm{GPa}) & \\
\text { Stiffness ratio: } & k_{\mathrm{n}} / k_{\mathrm{s}} & \end{array}$ & 3.5 \\
\hline
\end{tabular}

In this experiment, the values of the micro-parameters are shown in Table 3 . The seven groups of minimum ball radiuses, which were $0.1 \mathrm{~mm}, 0.15 \mathrm{~mm}, 0.2 \mathrm{~mm}, 0.25 \mathrm{~mm}$, $0.3 \mathrm{~mm}, 0.35 \mathrm{~mm}$, and $0.4 \mathrm{~mm}$, and 10 groups of ball radius ratios, which were $1,2,3,4,5,6,7,8,9$, and 10 , were set. There are $7 * 10=70$ combinations of particle geometric parameters. The contact normal bond strength $\sigma_{\mathrm{cn}}$ is $1 \mathrm{MPa}$, $5 \mathrm{MPa}, 15 \mathrm{MPa}, 20 \mathrm{MPa}$, and $30 \mathrm{MPa}$, while the contact shear bond strength $\tau_{\mathrm{cs}}$ is $50 \mathrm{MPa}$. The corresponding stiffness ratios are $0.02,0.1,0.3,0.4$, and 0.6 , in which $70 * 5=350$ tests were conducted in this study. The PFC model with various particle radii and various ball radius ratios was shown in Figure 2. 


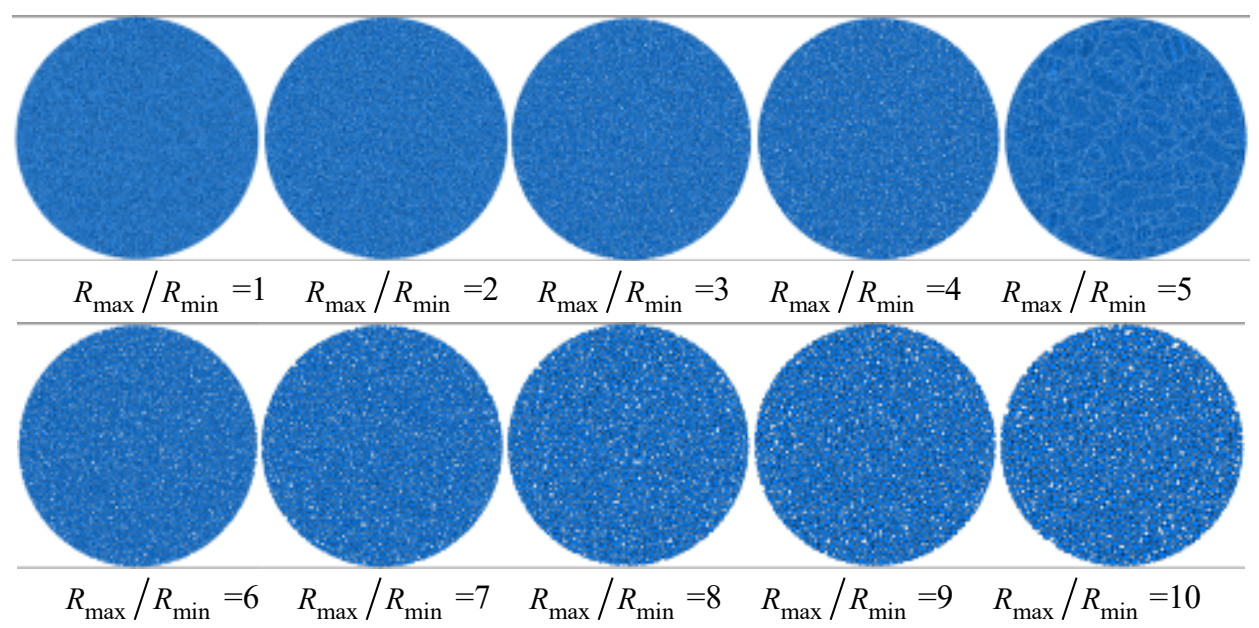

a $R_{\min }=0.1 \mathrm{~mm}, R_{\max } / R_{\min }=1-10$
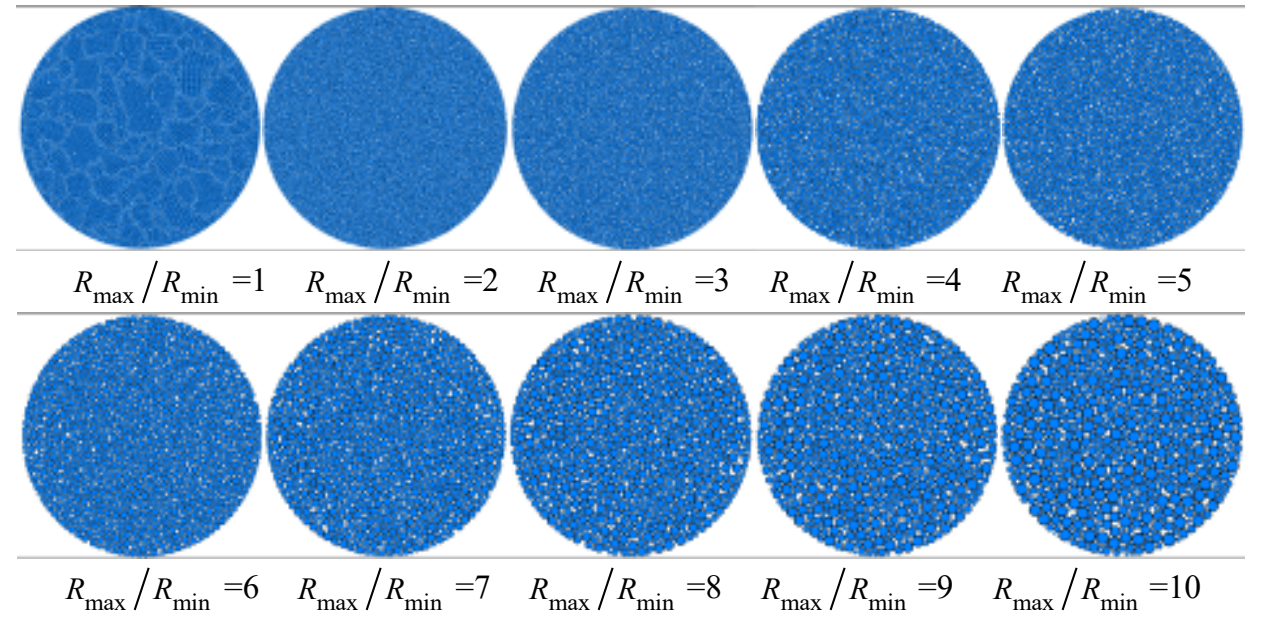

b $R_{\text {min }}=0.15 \mathrm{~mm}, R_{\max } / R_{\min }=1-10$
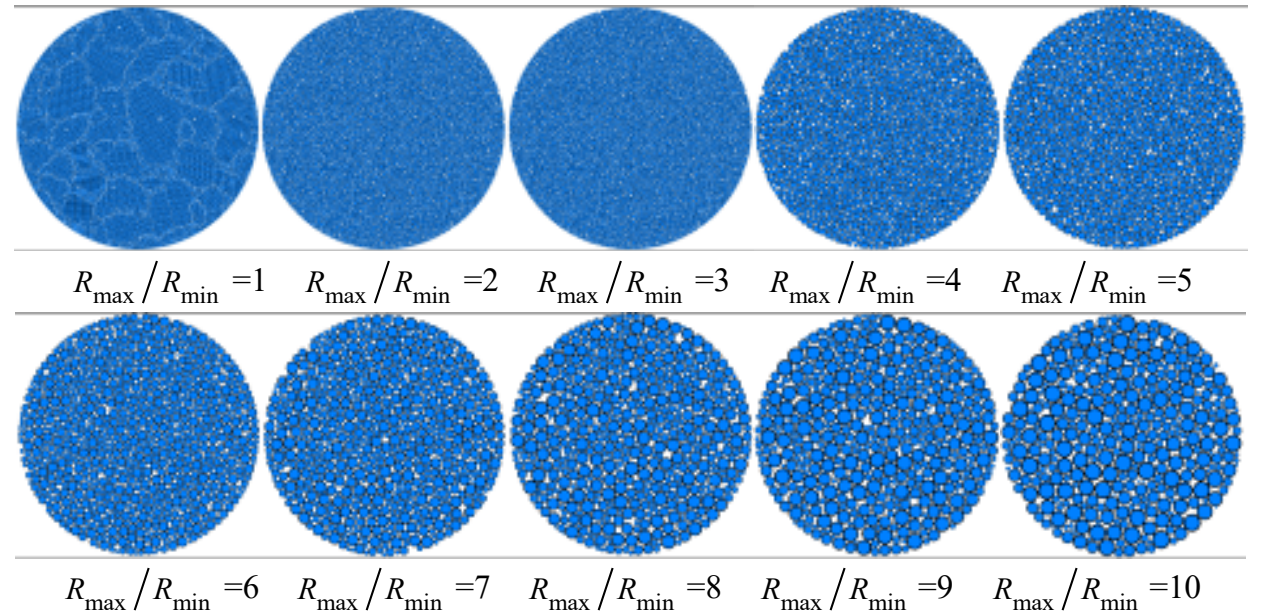

c $R_{\text {min }}=0.20 \mathrm{~mm}, R_{\text {max }} / R_{\text {min }}=1-10$

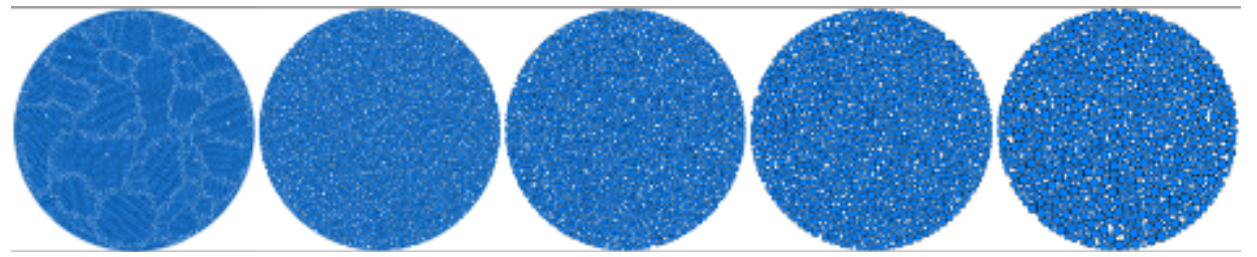

$R_{\text {max }} / R_{\text {min }}=1 \quad R_{\max } / R_{\min }=2 \quad R_{\max } / R_{\min }=3 \quad R_{\max } / R_{\min }=4 \quad R_{\max } / R_{\min }=5$ 


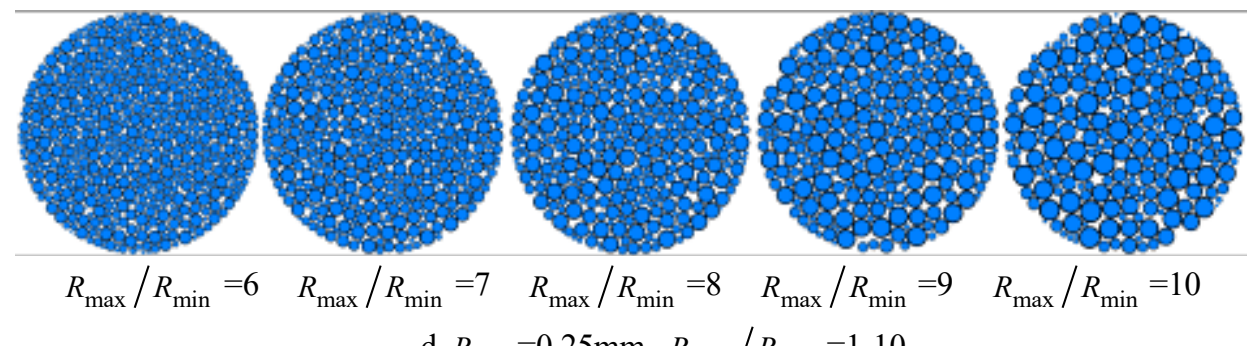

$\mathrm{d} R_{\text {min }}=0.25 \mathrm{~mm}, R_{\text {max }} / R_{\text {min }}=1-10$

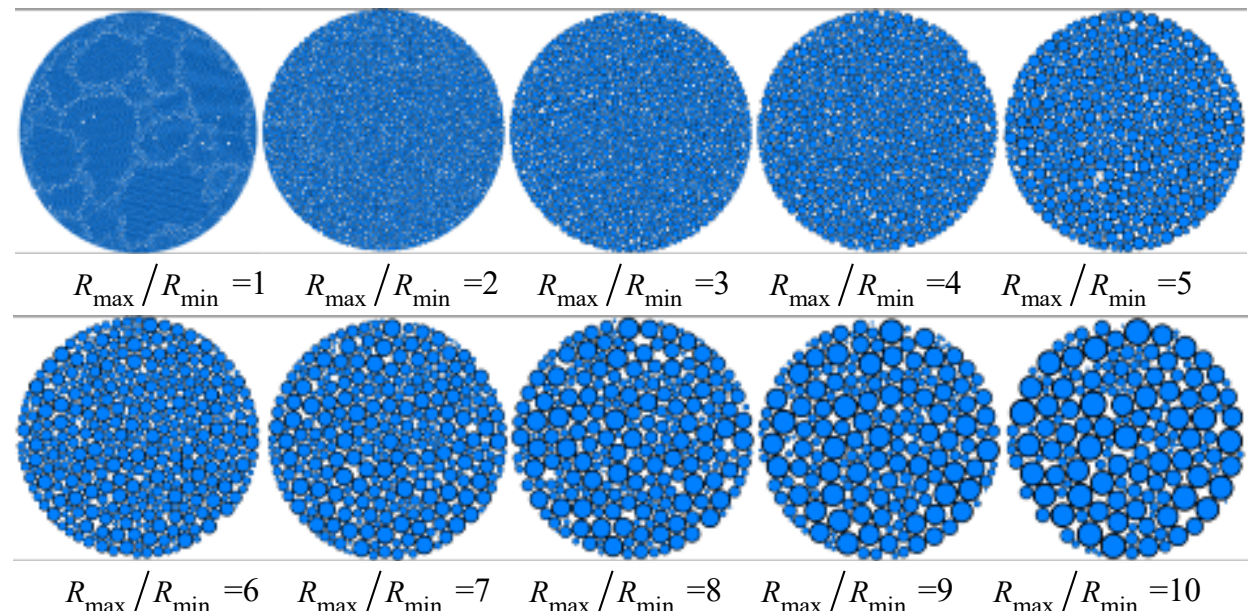

e $R_{\min }=0.30 \mathrm{~mm}, R_{\max } / R_{\min }=1-10$
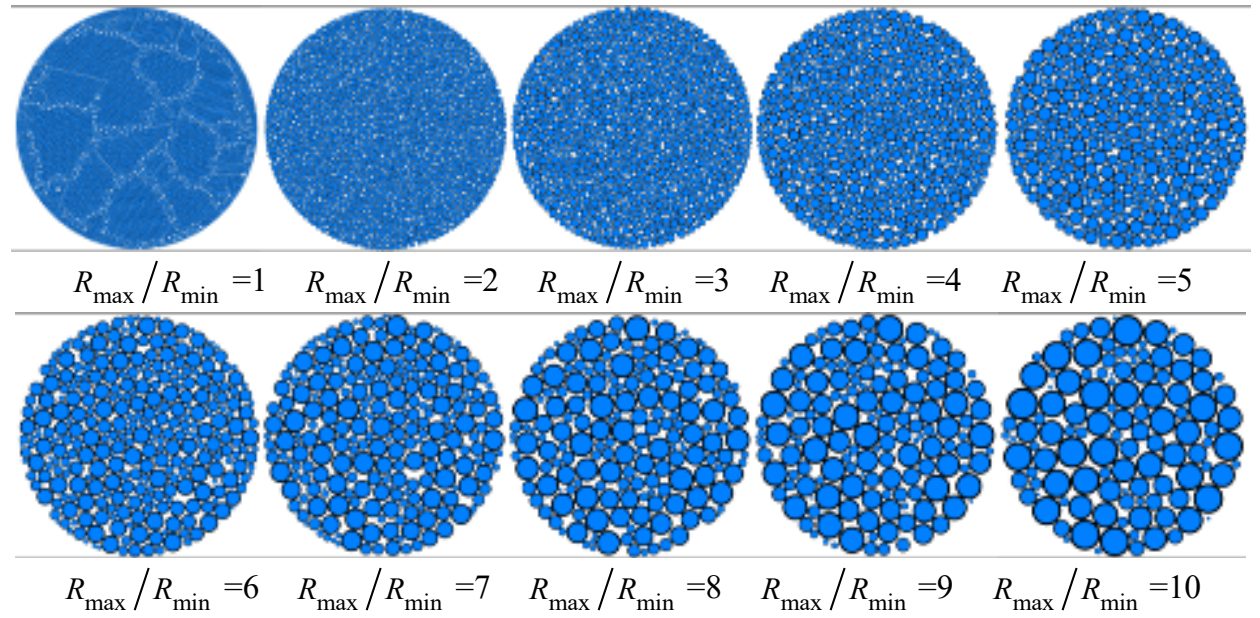

f $R_{\min }=0.35 \mathrm{~mm}, R_{\max } / R_{\min }=1-10$
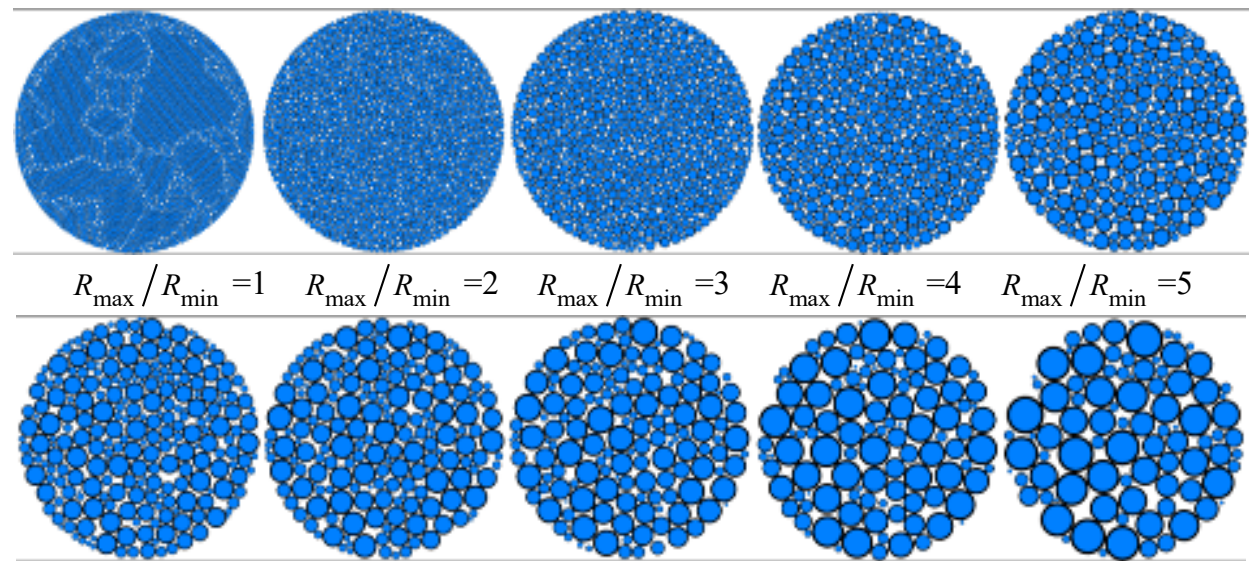

$R_{\text {max }} / R_{\text {min }}=6 \quad R_{\text {max }} / R_{\text {min }}=7 \quad R_{\text {max }} / R_{\text {min }}=8 \quad R_{\max } / R_{\min }=9 \quad R_{\max } / R_{\min }=10$

$\mathrm{g} R_{\min }=0.40 \mathrm{~mm}, R_{\max } / R_{\min }=1-10$

Fig. 2. The PFC Model of different ball radius of Brazilian test 
In Figure 2, a total of five strength parameters were set for each particle geometric model (a total of 70 groups) to study the influence of contact normal bond strength and particle geometric parameters on the macro tensile strength. a-g represented the PFC models corresponding to various ball radius ratios $R_{\max } / R_{\min }$ when the ball radius $R_{\min }$ is a fixed value.

\subsection{Loading method of Brazilian test in PFC2D}

The Brazilian test was simulated in PFC2D, while two "walls" with high rigidness were set on the upper and lower ends of the circular test specimen as the loading plates to ensure that the particles would not pass through the "walls" and the load was applied at a constant speed. At this loading speed, the test specimen should be in a quasi-static equilibrium state. Two methods proposed in the PFC user manual [2] can check the speed to ensure the quasi-static equilibrium state of the test. During the loading process, when the specimen is in the elastic deformation stage, the loading plate would stop and the change in the load on the loading plate was observed. If the load is constant, the numerical specimen is in a quasi-static equilibrium state. Another method monitors whether the function of the loading plat is consistent with the internal strain energy of particles. If they are equal in the elastic deformation stage, the test is in a quasi-static equilibrium state. This study used the first method to check the loading speed, in which the loading speed was $0.01 \mathrm{~m} / \mathrm{s}$.

\section{Result Analysis and Discussion}

\subsection{Results of the Brazilian test in PFC2D}

As seen from the PFC model in Figure 2, increasing the ball radius can substantially decrease the number of particles. For example, when the ball radius ranges from $0.15 \mathrm{~mm}$ to $0.30 \mathrm{~mm}$, there are $112,295,000$ particles. When the ball radius is $0.4 \mathrm{~mm}-3.2 \mathrm{~mm}$, the number of particles is only 114 . Consequently, the contact between the edge of the test piece and the "wall" (ball-wall contact) was significantly reduced. Moreover, the external load points at the top and bottom of the disc deviates from the vertical diameter direction, which makes the specimen rotate during loading. In this study, a total of 350 PFC numerical tests were performed, while the simulation results of each of the five tests (the geometric parameters of the particles are the same, the contact normal bond strength is $1 \mathrm{MPa}, 5 \mathrm{MPa}, 15 \mathrm{MPa}, 20 \mathrm{MPa}$, and $30 \mathrm{MPa}$ ) can obtain a macro tensile strength-micro contact normal bond strength relationship fitting curve. A total of 70 curves were obtained and shown in Figure 3.

The test results show that when the ball radius ratio $R_{\max } / R_{\min }$ is 9 and 10 (a total of 70 tests), most specimens were rotated before failure, making the test results unavailable. Therefore, the ball radius ratio $R_{\max } / R_{\min }$ of the PFC model should not exceed 8 , as the results of the Brazilian tensile test satisfied the requirements. After screening, 56 groups of the macro tensile strength-micro contact normal bond strength relationship fitting curves (calculation results of 280 PFC models) can be used for analysis.

The contact normal bond strength was linearly related to the Brazilian tensile strength. The range of the contact normal bond strength is $1.0 \mathrm{MPa}-30.0 \mathrm{MPa}$ (contact shear bond strength is $50.0 \mathrm{MPa}$ ). The Brazilian tensile strength

range obtained by the PFC numerical simulation is $0.0824 \mathrm{MPa}-10.705 \mathrm{MPa}$. The linear fitting results are shown in Figure 3, where a-g represented the fitting results corresponding to various ball radius ratios $R_{\max } / R_{\min }$ when the ball radius $R_{\min }$ is a fixed value.
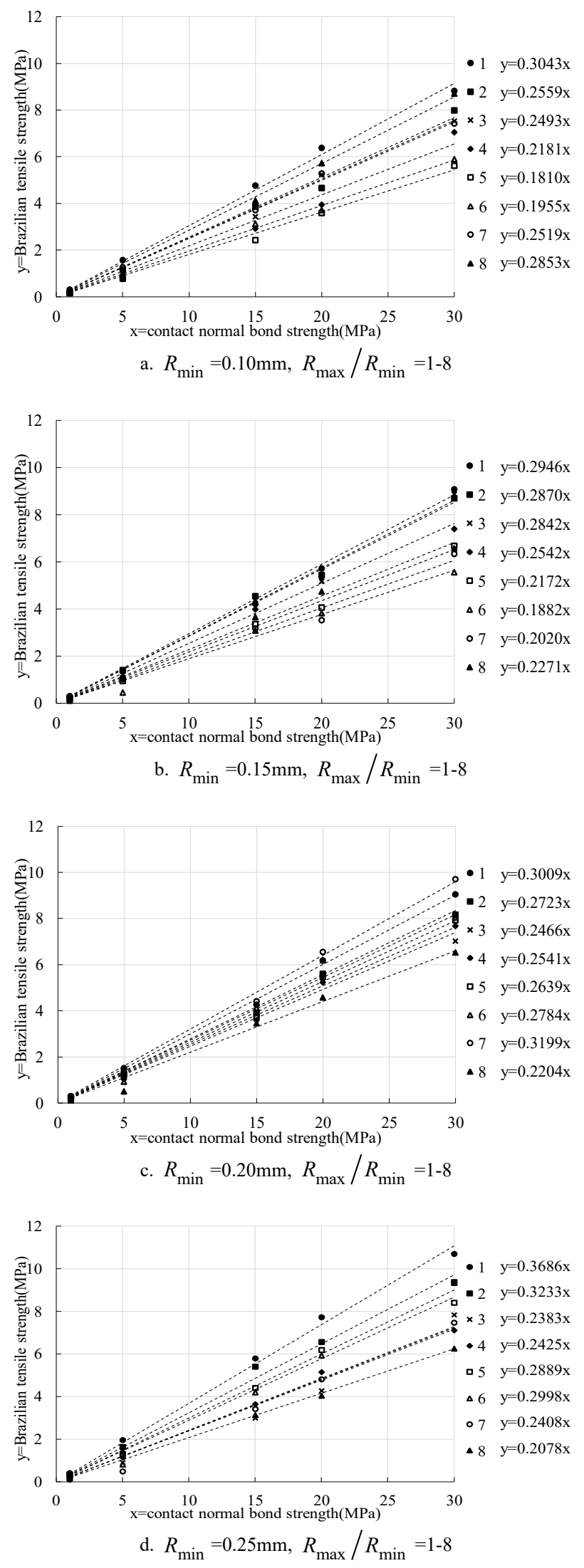

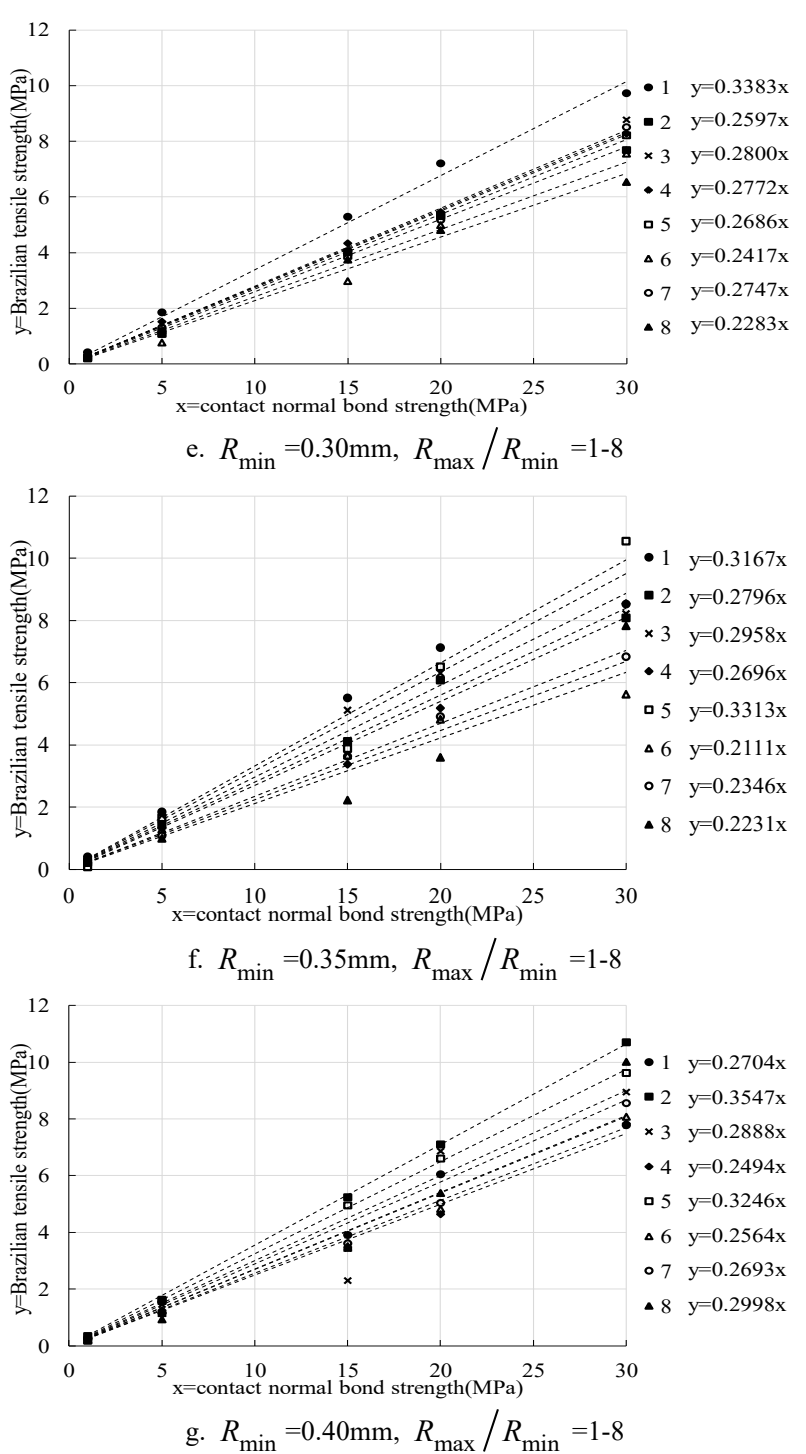

Fig. 3. Brazilian tensile strength $\sigma_{t}$ vs. contact normal bond strength $\sigma_{\mathrm{cn}}$
Fig. 3 shows the linear correlation between the Brazilian tensile strength $\sigma_{\mathrm{t}}$ and the contact normal bond strength $\sigma_{\text {cn }}$, which verifies the inference of Eq. (3) in Section 3.1. Eq. (4) is shown as follows:

$\sigma_{\mathrm{t}}=K \sigma_{\mathrm{cn}}$

where, $K$ is the scale coefficient. According to the 56 groups of PFC simulation results, the value of the scale coefficient $K$ and the fitting correlation coefficient are shown in Table 4.

As observed in Table 4, the correlation coefficient of the linear fitting ranges from 0.90 to 0.99 , indicating that the contact normal bond strength $\sigma_{\mathrm{cn}}$ and the macro tensile strength $\sigma_{t}$ have shown a good linear correlation. Within the selected range of the micro-parameters, the relationship between macro and micro tensile strength has the characteristics of Eq. (4). Eq. (4) can be solved by the Brazilian disk numerical simulation. The scale coefficient $K$ ranges from 0.1810 to 0.3686 .

\subsection{Effect of particle size on scale coefficient}

To study the change law of the scale coefficient $K$, the geometric parameters (minimum ball radius $R_{\min }$ and ball radius ratio $R_{\max } / R_{\min }$ ) were used as the horizontal axis and $K$ as the vertical axis to investigate the effect of the ball radius on the scale coefficient $K$. The relationship between the minimum ball radius $R_{\min }$ and the scale coefficient $K$ was shown in Figure 4, while the relationship between the ball radius ratio $R_{\max } / R_{\min }$ and the scale coefficient $K$ was described in Figure 5.

Table. 4. Fitting results of Scale coefficient $K$ of different particle size

\begin{tabular}{|c|c|c|c|c|c|c|c|c|}
\hline & & \multicolumn{7}{|c|}{ Minimum Ball Radius: $R_{\min }(\mathrm{mm})$} \\
\hline & & 0.1 & 0.15 & 0.2 & 0.25 & 0.3 & 0.35 & 0.4 \\
\hline \multirow{10}{*}{$\begin{array}{c}\text { Ball } \\
\text { Radius } \\
\text { Ratio: } \\
R_{\max } / R_{\min }\end{array}$} & 1 & $\begin{array}{c}0.3043 \\
(0.9954)\end{array}$ & $\begin{array}{c}0.2946 \\
(0.9970)\end{array}$ & $\begin{array}{c}0.3009 \\
(0.9982)\end{array}$ & $\begin{array}{c}0.3686 \\
(0.9952)\end{array}$ & $\begin{array}{c}0.3383 \\
(0.9923)\end{array}$ & $\begin{array}{c}0.3167 \\
(0.9992)\end{array}$ & $\begin{array}{c}0.2704 \\
(0.9856)\end{array}$ \\
\hline & 2 & $\begin{array}{c}0.2559 \\
(0.9915)\end{array}$ & $\begin{array}{c}0.2870 \\
(0.9965)\end{array}$ & $\begin{array}{c}0.2723 \\
(0.9984)\end{array}$ & $\begin{array}{c}0.3233 \\
(0.9922)\end{array}$ & $\begin{array}{c}0.2597 \\
(0.9985)\end{array}$ & $\begin{array}{c}0.2796 \\
(0.9918)\end{array}$ & $\begin{array}{c}0.3547 \\
(0.9993)\end{array}$ \\
\hline & 3 & $\begin{array}{c}0.2493 \\
(0.9922)\end{array}$ & $\begin{array}{c}0.2842 \\
(0.9890)\end{array}$ & $\begin{array}{c}0.2466 \\
(0.9871)\end{array}$ & $\begin{array}{c}0.2383 \\
(0.9690)\end{array}$ & $\begin{array}{c}0.2800 \\
(0.9923)\end{array}$ & $\begin{array}{c}0.2958 \\
(0.9741)\end{array}$ & $\begin{array}{c}0.2888 \\
(0.9990)\end{array}$ \\
\hline & 4 & $\begin{array}{c}0.2181 \\
(0.9781)\end{array}$ & $\begin{array}{c}0.2542 \\
(0.9950)\end{array}$ & $\begin{array}{c}0.2541 \\
(0.9964)\end{array}$ & $\begin{array}{c}0.2425 \\
(0.9970)\end{array}$ & $\begin{array}{c}0.2772 \\
(0.9986)\end{array}$ & $\begin{array}{c}0.2696 \\
(0.9839)\end{array}$ & $\begin{array}{c}0.2494 \\
(0.9912)\end{array}$ \\
\hline & 5 & $\begin{array}{c}0.1810 \\
(0.9929)\end{array}$ & $\begin{array}{c}0.2172 \\
(0.9948)\end{array}$ & $\begin{array}{c}0.2639 \\
(0.9976)\end{array}$ & $\begin{array}{c}0.2889 \\
(0.9943)\end{array}$ & $\begin{array}{c}0.2686 \\
(0.9971)\end{array}$ & $\begin{array}{c}0.3313 \\
(0.9763)\end{array}$ & $\begin{array}{c}0.3246 \\
(0.9991)\end{array}$ \\
\hline & 6 & $\begin{array}{c}0.1955 \\
(0.9962)\end{array}$ & $\begin{array}{c}0.1882 \\
(0.9847)\end{array}$ & $\begin{array}{c}0.2784 \\
(0.9844)\end{array}$ & $\begin{array}{c}0.2980 \\
(0.9877)\end{array}$ & $\begin{array}{c}0.2417 \\
(0.9797)\end{array}$ & $\begin{array}{c}0.2111 \\
(0.9451)\end{array}$ & $\begin{array}{c}0.2564 \\
(0.9907)\end{array}$ \\
\hline & 7 & $\begin{array}{c}0.2519 \\
(0.9976)\end{array}$ & $\begin{array}{c}0.2020 \\
(0.9842)\end{array}$ & $\begin{array}{c}0.3199 \\
(0.9967)\end{array}$ & $\begin{array}{c}0.2408 \\
(0.9833)\end{array}$ & $\begin{array}{c}0.2747 \\
(0.9957)\end{array}$ & $\begin{array}{c}0.2346 \\
(0.9962)\end{array}$ & $\begin{array}{c}0.2693 \\
(0.9870)\end{array}$ \\
\hline & 8 & $\begin{array}{c}0.2853 \\
(0.9939)\end{array}$ & $\begin{array}{c}0.2271 \\
(0.9940)\end{array}$ & $\begin{array}{c}0.2204 \\
(0.9857)\end{array}$ & $\begin{array}{c}0.2078 \\
(0.9924)\end{array}$ & $\begin{array}{c}0.2283 \\
(0.9904)\end{array}$ & $\begin{array}{c}0.2231 \\
(0.9069)\end{array}$ & $\begin{array}{c}0.2998 \\
(0.9547)\end{array}$ \\
\hline & 9 & Not Available & Not Available & Not Available & Not Available & Not Available & Not Available & Not Available \\
\hline & 10 & Not Available & Not Available & Not Available & Not Available & Not Available & Not Available & Not Available \\
\hline
\end{tabular}

Note: the data in brackets were the linear fitting correlation coefficients. 


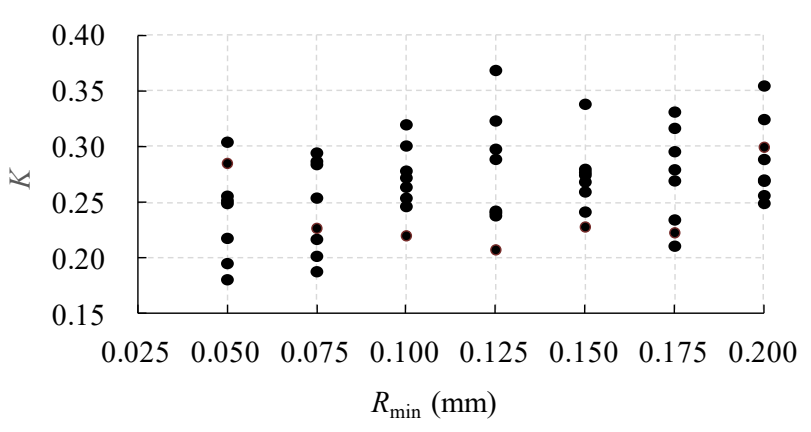

Fig. 4. Scale coefficient $K$ vs. the minimum ball radius $R_{\min }$

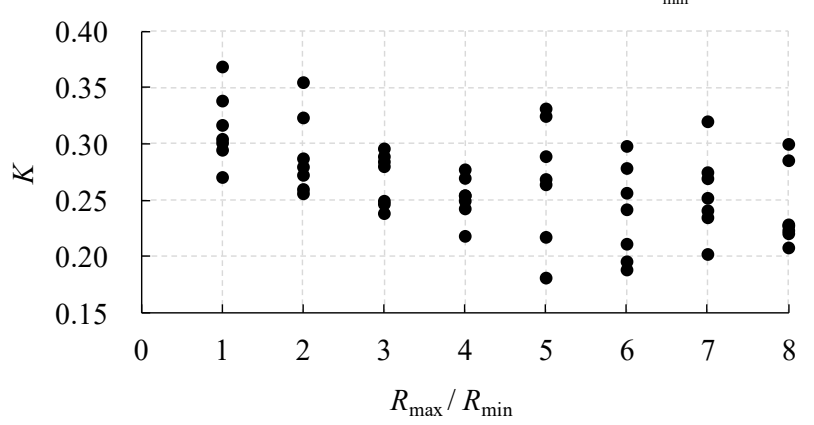

Fig. 5. Scale coefficient $K$ vs. the ball radius ratio $R_{\max } / R_{\min }$

As seen from Figures 4 and 5, as the minimum ball radius $R_{\text {min }}$ increases, the scale coefficient $K$ generally increases, while the ball radius ratio $R_{\max } / R_{\min }$ increases, the scale coefficient $K$ first decreases and then increases. When $R_{\max } / R_{\min }$ is not greater than 4 , the data shows a strong regularity and was basically linearly related. There was no obvious linear correlation between the scale coefficient $K$ and the ball radius, while the regularity of the change is weak. Not only does it limits the range of the scale coefficient $K$, but also makes it difficult to solve the interpolation.

\subsection{Verification of the scale coefficient}

The simulation object was sandstone and the tensile strength measured by the Brazilian test was 9.08MPa. Five PFC models were established for the simulation. The minimum ball radius $R_{\min }$ was $0.14 \mathrm{~mm}, 0.18 \mathrm{~mm}, 0.23 \mathrm{~mm}, 0.27 \mathrm{~mm}$, and $0.37 \mathrm{~mm}$, while the ball radius ratio $R_{\max } / R_{\min }$ was 3.4 , 7.6, 5.8, 1.5, and 2.7.

Table 5. Contact normal bond strength calculated from the Brazilian tensile strength

\begin{tabular}{c|c|c|c}
\hline $\begin{array}{c}\text { Test } \\
\text { number }\end{array}$ & $\begin{array}{c}\text { Brazilian tensile } \\
\text { strength } \\
\sigma_{\mathrm{t}} \mathbf{( M P a )}\end{array}$ & $\begin{array}{c}\text { scale } \\
\text { coefficient } \\
K\end{array}$ & $\begin{array}{c}\text { contact normal } \\
\text { bond strength } \\
\sigma_{\mathrm{cn}}(\mathbf{M P a})\end{array}$ \\
\hline 1 & 9.08 & 0.2651 & 34.25 \\
2 & 9.08 & 0.2429 & 37.38 \\
3 & 9.08 & 0.2879 & 31.54 \\
4 & 9.08 & 0.3272 & 27.75 \\
5 & 9.08 & 0.2980 & 30.47 \\
\hline
\end{tabular}

According to the linear interpolation method, the scale coefficient $K$ can be obtained from Table 4, while the contact normal bond strength $\sigma_{\text {cn }}$ can be obtained by Eq. (4), as shown in Table 5. The micro-parameters of the five PFC models and the numerical simulation results are listed in Table 6. Figure 6 compares the Brazilian tensile test and the PFC numerical experiment.

The minimum error between the PFC numerical simulation result and the actual measurement result is $1.10 \%$, and the maximum error is $14.86 \%$. Both of them are smaller than $15 \%$, indicating that the proposed method for determining the contact normal bond strength is basically feasible. The accuracy is high when a small minimum ball radius is selected. In addition, the micro-mechanical parameters are different from the values in Table 3 in Section 3.3, which can verify the adaptability of Eq. (4) in Section 4.1.

Table 6. The micro-parameters for numerical simulation of PFC2D

\begin{tabular}{|c|c|c|c|c|c|c|c|c|c|}
\hline \multirow{2}{*}{$\begin{array}{c}\text { Test } \\
\text { number }\end{array}$} & \multicolumn{7}{|c|}{ Micro-parameters of CBM } & \multirow{2}{*}{$\frac{\text { PFC Result }}{\sigma_{\mathrm{t}}(\mathrm{MPa})}$} & \multirow{2}{*}{$\begin{array}{c}\text { Relative error } \\
\delta(\%)\end{array}$} \\
\hline & $R_{\min }(\mathbf{m m})$ & $R_{\max } / R_{\min }$ & $E_{\mathrm{c}}$ (GPa) & $k_{\mathrm{n}} / k_{\mathrm{s}}$ & $\sigma_{\mathrm{cn}}(\mathbf{M P a})$ & $\sigma_{\mathrm{cn}} / \tau_{\mathrm{cs}}$ & $\mu$ & & \\
\hline 1 & 0.14 & 3.4 & 10 & 3.5 & 34.25 & 0.4 & 1.7 & 9.70 & 6.83 \\
\hline 2 & 0.18 & 7.6 & 16 & 2.0 & 37.38 & 0.6 & 1.0 & 8.98 & 1.10 \\
\hline 3 & 0.23 & 5.8 & 12 & 3.0 & 31.54 & 0.5 & 1.5 & 10.19 & 12.22 \\
\hline 4 & 0.27 & 1.5 & 8 & 2.5 & 27.75 & 0.7 & 1.8 & 8.27 & 8.92 \\
\hline 5 & 0.37 & 2.7 & 13 & 2.3 & 30.47 & 0.2 & 2.3 & 10.43 & 14.86 \\
\hline
\end{tabular}

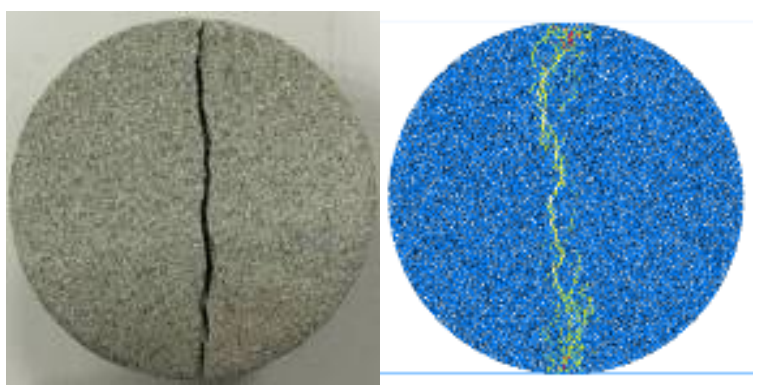

Fig. 6. Brazilian test vs. PFC simulation

The minimum error between the PFC numerical simulation result and the actual measurement result is $1.10 \%$, and the maximum error is $14.86 \%$. Both of them are smaller than $15 \%$, indicating that the proposed method for determining the contact normal bond strength is basically feasible. The accuracy is high when a small minimum ball radius is selected. In addition, the micro-mechanical parameters are different from the values in Table 3 in Section 3.3, which can verify the adaptability of Eq. (4) in Section 4.1.

\section{Conclusions}

To reveal the effects of the contact normal bond strength on the Brazilian tensile strength, this study established the qualitative relationship between the PFC contact normal bond strength and the Brazilian tensile strength through theoretical derivation. The regression relationship between the contact normal bond strength and the Brazilian tensile strength was analyzed based on the calculation of 350 PFC models (280 of which are valid). The following conclusions could be drawn: 
(1) The Brazilian tensile strength is proportional to the contact normal bond strength, in which the Brazilian tensile strength can be expressed as the product of the contact normal bond strength and the scale coefficient $K$. To ensure the validity of the simulation results, the ball radius ratio was recommended to be less than 8 . Otherwise, the test specimen will rotate during the loading process, thus influencing the simulation results. The 56 groups (the effective calculation results of 280 PFC models) of the Brazilian tensile numerical simulation results show that the macro- and micro-tensile strength shows a significant linear correlation and the correlation coefficient of linear fitting ranges from 0.90 to 0.99 .

(2) In this study, the fitted scale coefficient $K$ is in the range of $0.1810-0.3686$, whereas the scale coefficient $K$ was related to the geometric parameters of the particles. As the minimum ball radius increases, the number of particles in the test specimen decreases, and the test specimen enters the heterogeneous state. Consequently, the difference in the mechanical properties of the test specimen caused the various particle distribution states to expand. The regularity of the $K$ distribution worsens as the minimum ball radius increases.

(3) Based on the scale coefficient table obtained in this study, the contact normal bond strength of the PFC numerical simulation can be determined by the rapid look-up table of the Brazilian tensile strength. According to the five cases, the minimum error of the Brazilian tensile strength simulation is $1.1 \%$, whereas the maximum error is $14.86 \%$. When the smaller minimum ball radius and ball radius ratio are selected, the Brazilian tensile strength simulated by PFC becomes accurate.
Thus, the quantitative relationship between the contact normal bond strength and the Brazilian tensile strength was established through a theoretical derivation and PFC numerical simulation, in which the Brazilian tensile strength can be expressed as the product of the contact normal bond strength and the scale coefficient. A method for determining the contact normal bond strength was proposed. Meanwhile, the physical significance of the contact normal bond strength of the CBM was revealed to a certain extent. However, the contact shear bond strength, friction coefficient, contact modulus, and stiffness ratio were ignored. Therefore, the effects of the contact shear bond strength, friction coefficient, contact modulus, and stiffness ratio on the Brazilian tensile strength should be considered in future studies. Such an action should be taken to correct the quantitative relationship between the contact normal bond strength and the Brazilian tensile strength and to obtain accurate contact normal bond strength.

\section{Acknowledgements}

This work was supported by the Fundamental Research Funds for Central Universities (Project No. 2019CDSKXYJSG0041), the Youth Project of Science and Technology Research Program of Chongqing Education Commission of China (Project No. KJQN201800125), the City Science of Chongqing (Integration and demonstration of key technology research of prefabricated housing construction, 2015 No. 01), and Chongqing Graduate Research and Innovation Foundation (Grant No. CYS19016).

This is an Open Access article distributed under the terms of the Creative Commons Attribution License

\section{References}

1. Potyondy, D.O., Cundall, P.A., "A bonded-particle model for rock". International Journal of Rock Mechanics and Mining Science, 41(8), 2014, pp. 1329-1364.

2. Itasca Consulting Group, "PFC-Particle flow code in 2 and 3 dimensions(version 5.0), User's Guide”. Minnesota, 2016, pp. 2-35.

3. Huang, H.Y, "Discrete element modeling of tool rock interaction". Ph.D. thesis of University of Minnesota, America, 1999, pp. 1-30.

4. Wang, Y., Tonon, F., "Modeling Lac du Bonnet granite using a discrete element model". International Journal of Rock Mechanics and Mining Sciences, 46 (7), 2009, pp. 1124-1135.

5. Xu, X.M., Ling, D.S., Chen, Y.M., Huang, B., "Correlation of microscopic and macroscopic elastic constants of granular materials based on linear contact model". Chinese Journal of Geotechnical Engineering, 32(7), 2010, pp. 991-998.

6. Wang, T., Zhou, W.B., Chen, J.H., "Simulation of hydraulic fracturing using particle flow method and application in a coal mine". International Journal of Coal Geology, 121, 2014, pp. 1-13.

7. Coetzee, C.J., "Review: Calibration of the discrete element method". Powder Technology, 310, 2017, pp. 104-142.

8. Yang, B., Jiao, Y., Lei, S., "A study on the effects of microparameters on macroproperties for specimens created by bonded particles". International Journal for Computer-Aided Engineering and Software, 23(6), 2006, pp. 607-631.

9. Ding, X.B., Zhang, L.Y., Zhu, H.H., "Effect of model scale and particle size distribution on PFC3D simulation results". Rock Mechanics and Rock Engineering, 47(6), 2014, pp. 2139-2156.

10. Nohut, S., Cevik, A., "Investigation of micro-macroscale interaction of heterogeneous materials by a parallel-bonded particle model and introduction of new microparameter determination formulations". International Journal for Multiscale Computational Engineering, 12(1), 2014, pp. 1-12.

11. Wong, L.N.Y., Zhang, X.P., "Size effects on cracking behavior of flaw-containing specimens under compressive loading". Rock Mechanics and Rock Engineering, 47(5), 2014, pp. 1921-1930.
12. Li, K.M., Li, Y.H., Xu, S., An, L., "Method to determine microscopic parameters of PFC2D numerical model". Journal of Northeastern University(Natural Science), 37(4), 2016, pp. 563-567.

13. Afolagboye, L.O., He, J. Wang, S., "Experimental study on cracking behaviour of moulded gypsum containing two non-parallel overlapping flaws under uniaxial compression". Acta Mechanica Sinica, 33 (2), 2017, pp. 394-405.

14. Wang, X., Tian, L., "Mechanical and crack evolution characteristics of coal-rock under different fracture-hole conditions: a numerical study based on particle flow code". Environmental Earth Sciences, 77(8), 2018, pp. 297.

15. Mehranpour, M.H., Kulatilake, P.H.S.W., "Comparison of six major intact rock failure criteria using a particle flow approach under true-triaxial stress condition". Geomechanics and Geophysics for Geo-Energy and Geo-Resources, 2(4), 2016, pp. 203-229.

16. Jeoungseok, Yoon., "Application of experimental design and optimization to PFC model calibration in uniaxial compression simulation". International Journal of Rock mechanics and Mining Sciences, 44(5), 2007, pp. 871-889.

17. Deng S.X., Zheng Y.L., Feng L.P., Zhu P.Y., Ni, Y., “Application of design of experiments in microscopic parameter calibration for hard rocks of PFC3D model". Chinese Journal of Geotechnical Engineering, 41(4), 2019, pp. 655-664.

18. Xue, X.L., Wu, S.W., Gao, Y.T., Xu, M.F., "Effects of microstructure and micro-parameters on Brazilian tensile strength using flat-joint model". Rock Mechanics and Rock Engineering, 49(9), 2016, pp. 3575-3595.

19. Castro-Filgueiraa, U., Alejanoa, L.R., Arzúa, J., Mas Ivars, D., "Sensitivity analysis of the micro-parameters used in a PFC analysis towards the mechanical properties of rocks". Procedia Engineering, 191, 2017, pp. 488-495.

20. Chen, P., "Effects of microparameters on macroparameters of flatjointed bonded-particle materials and suggestions on trial-and-error method". Geotechnical and Geological Engineering, 35(2), 2017, pp. 663-677. 
21. Wu, S.C., Ma, J., Cheng Y., Xu M.F., HUANG X Q.., "Numerical analysis of the flattened Brazilian test: failure process, recommended geometric parameters and loading conditions". Engineering Fracture Mechanics, 204, 2018, pp. 288-305.

22. Torabi, A.R., Etesam, S., Sapora, A., "Size effects on brittle fracture of Brazilian disk samples containing a circular hole". Engineering Fracture Mechanics, 186, 2017, pp. 496-503.

23. Yang S.Q., LI Y,HUANG Y H., "Size effects on brittle fracture of Brazilian disk samples containing a circular hole". Engineering Fracture Mechanics, 186, 2017, pp. 496-503.

24. Akram, M.S., Sharrock, G.B., Mitra, R., "Investigating mechanics of conglomeratic rocks: influence of clast size distribution, scale and properties of clast and interparticle cement". Bulletin of Engineering Geology and the Environment, 78(4), 2019, pp. 27692788 .
25. Liu, X.R., Fu, Y., Zheng, Y.R., Zhong, Z.L., "Relation between meso-parametiers of Particle Flow Code and fracture toughness of rock". Chinese Journal of Rock Mechanics and Engineering, 30(10), 2011, pp. 2084-2089.

26. Zhang Z.X., "An empirical relation between mode I fracture toughness and the tensile strength of rock". International Journal of Rock mechanics and Mining Sciences, 39(4), 2002, pp. 1-6.

27. Ulusay, R., Hudson J.A., "The ISRM suggested methods for rock characterization, testing and monitoring: 2007-2014". Berlin: Springer Berlin Heidelberg, German, 2015, pp. 1-22.

28. The National Standards Compilation Group of People's Republic of China, "Standard for Tests Method of Engineering Rock Masses(GB/T50266-2013)". Beijing: China Planning Press, China, 2013, pp. 1-28.

29. Shi, C., Zhang, Q., Wang, S.N., "Numerical simulation and its application of $P F C$ ". Beijing: China Architecture \& Building Press, China, 2018, pp. 10-38. 